\title{
Association Between Gastrointestinal Events and Health Care Resource Utilization Among Patients with 0steoporosis: Analysis of a U.S. Managed Care Population
}

\author{
Ankita Modi, PhD; Deborah T. Gold, PhD; Xiaoqin Yang, PhD; \\ Chun-Po Steve Fan, PhD; and Shiva G. Sajjan, PhD
}

\begin{abstract}
BACKGROUND: Among patients on osteoporosis therapy, including oral bisphosphonates (BIS), upper gastrointestinal (GI) conditions have been linked with lower adherence to treatment and increased treatment discontinuation in clinical practice. Patients who are nonadherent to treatment have a higher risk of osteoporotic fractures and, consequently, have greater use of health care services. The burden of upper gastrointestinal events on health care resource utilization (HCRU) among women initiating oral BIS has not been well investigated.
\end{abstract}

OBJECTIVE: To examine the association of upper GI events and HCRU in women initiating oral BIS.

METHODS: Using a U.S. national claims database, this retrospective study identified women aged $\geq 55$ years who were prescribed oral BIS during 2001-2011 and had no history of GI events 12 months prior to treatment initiation. Patients with medical claims for an upper Gl event $\leq 4$ months posttreatment initiation were cases; all others were controls. The date of the first upper GI event among cases and a randomly assigned date $\leq 4$ months posttreatment initiation among controls was the index date. Cases were matched 1:1 to controls by propensity scores derived from logistic regression of pre-index patient characteristics. Outcomes were all-cause and osteoporosis (OP)-related HCRU in the 6-month post-index period. Differences were assessed using McNemar's test.

RESULTS: Of the 62,863 eligible patients, 4,751 (7.6\%) experienced an upper GI event $\leq 4$ months posttreatment initiation (cases); 4,739 cases were matched with 4,739 controls. Compared with controls, cases had higher rates of all-cause HCRU (outpatient: $99.3 \%$ vs. $87.8 \%$; inpatient: $20.2 \%$ vs. $6.4 \%$; emergency room [ER]: $12.5 \%$ vs. $7.4 \%$; all $P<0.0001$ ) and OP-related HCRU (outpatient: $24.6 \%$ vs. $18.2 \%$; inpatient: $3.4 \%$ vs. $1.0 \%$; ER: $0.7 \%$ vs. $0.4 \%$; all $P<0.05$ ).

CONCLUSIONS: Patients with upper GI events had higher rates of all-cause and OP-related health care utilization. Upper GI events may pose an incremental HCRU burden among patients initiating BIS.

J Manag Care Spec Pharm. 2015;21(9):811-21

Copyright @ 2015, Academy of Managed Care Pharmacy. All rights reserved.

\section{What is already known about this subject}

Previous observational studies have linked upper gastrointestinal conditions among patients taking osteoporosis therapies, including oral bisphosphonates, to poor adherence to treatment and therapy discontinuation.
Patients who are nonadherent or nonpersistent to osteoporosis therapy are at higher risk of fracture and consequently have greater use of health care services.

The association between gastrointestinal events and health care resource utilization has not been well investigated.

\section{What this study adds}

This study evaluated the association between upper gastrointestinal events and health care resource utilization among women who had initiated oral bisphosphonate treatment and had no recent history of gastrointestinal diagnoses.

Following initiation of oral bisphosphonate treatment, women who experienced upper gastrointestinal events incurred significantly greater all-cause and osteoporosis-related medical resource utilization than their counterparts who did not experience upper gastrointestinal events.

Upper gastrointestinal events were associated with 1.5 to 3.5 greater odds of utilizing osteoporosis-related inpatient, outpatient, and emergency room services. $\square$ ral bisphosphonates (BIS) are the most commonly prescribed first-line treatment for osteoporosis (OP) in postmenopausal women in the United States and have proven to be effective in reducing the risk of fracture in clinical trials. ${ }^{1-7}$ However, gastrointestinal (GI) events are a common complaint of patients taking BIS, often manifesting as dyspepsia, nausea, abdominal pain, and, less frequently, esophagitis and esophageal/duodenal ulcers. $^{8-11}$ In clinical practice, approximately $25 \%$ of women with OP experience GI events before OP treatment initiation. ${ }^{8}$ Previous studies have shown that the proportion of women experiencing GI events prior to initiating oral BIS therapy is similar to the proportion of women experiencing new GI events after initiating oral BIS therapy. ${ }^{8}$ However, occurrence of GI events may pose an incremental health care resource burden.

The consequences of GI events can be poor adherence to therapy and, ultimately, negative clinical and economic outcomes. Patients taking oral BIS who are most symptomatic for 


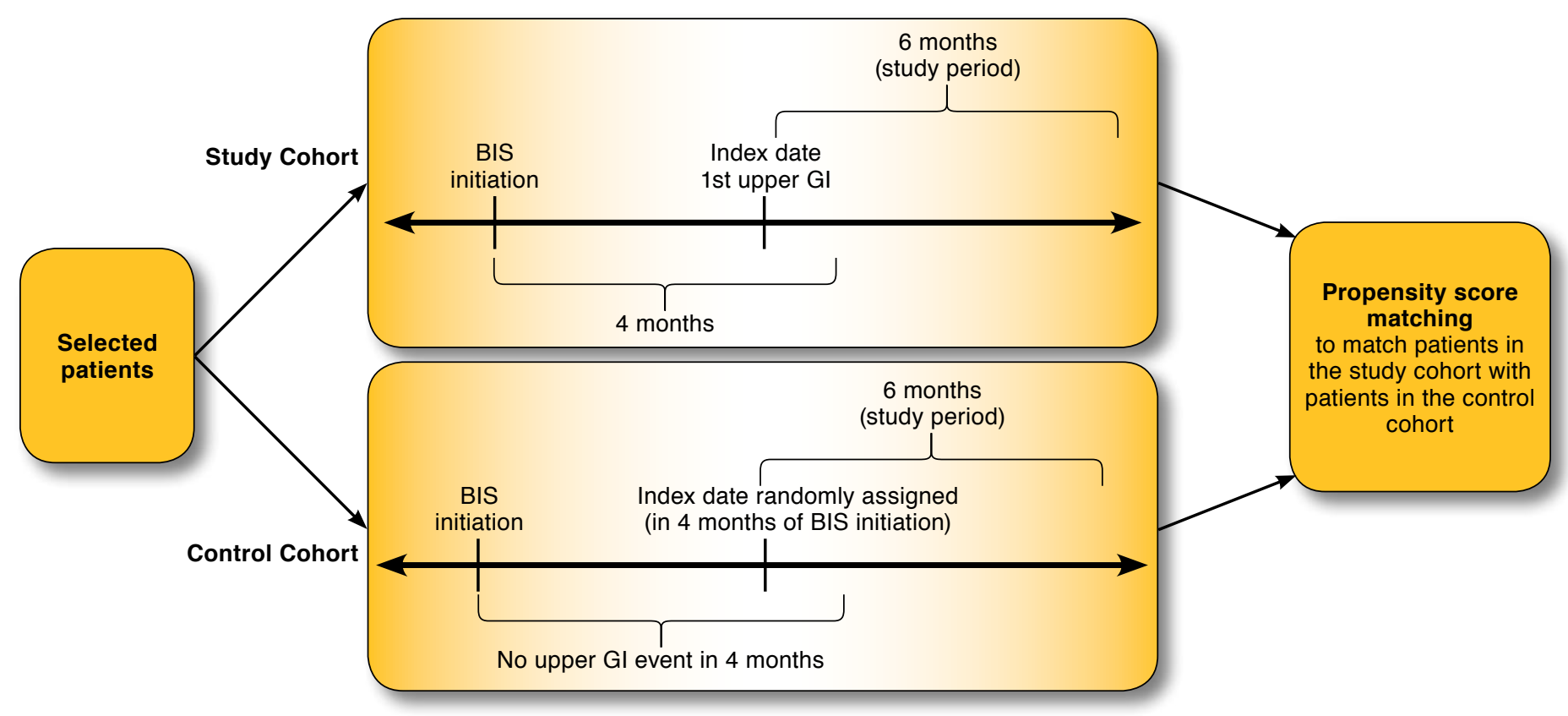

BIS= bisphosphonate; GI = gastrointestinal .

side effects have higher odds of nonadherence to therapy, ${ }^{12}$ and in clinical practice, $26 \%$ to $76 \%$ of patients who discontinued oral BIS therapy did so primarily because of GI intolerance. ${ }^{13-15}$ Patients who are nonadherent to OP therapies, including BIS, are at higher risk of vertebral and nonvertebral fractures, incur higher medical costs, and are more likely to be hospitalized. ${ }^{16-21}$

GI events in women initiating primarily oral BIS medications have also been linked to diminished health-related quality of life and lower treatment satisfaction, which may lead to treatment discontinuation, worse clinical outcomes, and, ultimately, greater use of health care services. ${ }^{8}$ However, the burden of GI events to health care resource utilization in women taking oral BIS has not been well investigated. The objective of this study was to examine the association of upper GI events with all-cause and OP-related health care resource utilization among women who were initiating BIS.

\section{Methods}

A retrospective matched cohort study design was used to examine the association between upper GI events after initiation of treatment and all-cause and OP-related health care resource utilization among osteoporotic patients who were prescribed oral BIS therapy. All data were de-identified and accessed in compliance with the Health Insurance Portability and Accountability Act privacy guidelines. ${ }^{22}$

\section{Data Source}

We used the i3 Invision Datamart database for analysis. This large national claims database was designed primarily to support health care outcomes research and other research initiatives. The database contained health care claims for more than 80 million managed care enrollees in more than 45 health plans throughout the United States during 2001-2011. Data elements used in the current analysis included health plan enrollment records, patient demographics, type of insurance, medical claims (from inpatient and outpatient facilities), and prescription pharmacy claims. The database included data on approximately 3 million subjects with a diagnosis of OP, OP-related fracture, and/or a prescription for a medication used to treat or prevent OP (e.g., BIS and estrogens). Primary and secondary diagnoses from the medical records were identified by the International Classification of Diseases, Ninth Revision, Clinical Modification (ICD-9-CM) codes; procedures codes were identified by Current Procedural Terminology (CPT) codes and prescription pharmacy records were identified by National Drug Code numbers.

\section{Patient Identification}

We first identified women who initiated oral BIS therapy during January 1, 2001, to June 30, 2011. Oral BIS therapy was defined as the presence of a prescription claim for alendronate, ibandronate, or risedronate. The first pharmacy claim for BIS 
was the treatment initiation date. Only patients aged $\geq 55$ years as of the treatment initiation date and those with continuous health plan enrollment (with medical and pharmacy benefits) for at least 1 year before and 10 months after the treatment initiation date were selected. Patients were excluded if they had evidence of Paget's disease (ICD-9-CM code 731.0) ever in the claims history or malignant neoplasm (ICD-9-CM codes 140-170, 173-208, 230-239) in the year before and 10 months after the treatment initiation date. In addition, patients were excluded if they were prescribed with $\geq 2$ BIS agents or $\geq 1$ non-BIS agents (i.e., raloxifene) on the treatment initiation date. Because patients with a history of GI events are at increased risk of subsequent GI events, the occurrence of some GI events after treatment initiation may be associated with GI events prior to treatment initiation. ${ }^{23}$ To eliminate potential bias associated with GI events prior to treatment initiation on health care utilization after treatment initiation, patients experiencing any (upper or lower) GI events during the 1-year period before treatment initiation were also excluded. GI events (upper or lower) were defined by the presence of a medical claim (inpatient or outpatient) with a GI-related ICD-9-CM diagnostic code or CPT procedural code. The relevant codes are shown in the Appendix (available in online article).

\section{Definition of Cases and Controls}

Patients who met inclusion criteria were grouped into 2 cohorts: case and control (Figure 1). The case cohort included patients who experienced $\geq 1$ upper GI event within the first 4 months following the date of treatment initiation. The date of the first upper GI event after treatment initiation was defined as the index date for cases. The control cohort included patients who did not experience any upper GI event within the first 4 months following treatment initiation. A randomly assigned date within the first 4 months following treatment initiation was set as the index date for controls. The random assignment of the index date for controls was based on the empirical distribution of time to the index date for the case group. For both groups, the follow-up period extended from the index date to 6 months after the index date. Upper GI events were defined as the presence of a medical claim (inpatient or outpatient) with an upper GI-related ICD-9-CM diagnostic code (ICD-9-CM codes included 530.81, 530.82, 531.xx, 532.xx, 533.xx, 578.xx, $530.1 x, 530.2 x, 530.3 x, 530.4 x, 530.5 x, 530.6 x, 530.7 x$, 535.0x, 535.4x, 535.5x, 535.6x, 536.2x, 536.8x, 787.0x, 787.1x, 787.2x, and 789.0x). For example, upper GI events included esophagitis, ulcer of esophagus, stricture of esophagus, perforation of esophagus, dyskinesia of esophagus, diverticulum of esophagus, gastroesophageal laceration-hemorrhage syndrome, esophageal reflux, esophageal hemorrhage, gastric ulcer, duodenal ulcer, peptic ulcer, gastritis, duodenitis, persistent vomiting, dyspepsia, GI hemorrhage, nausea and vomiting, heartburn, dysphagia, and abdominal pain (see Appendix).

\section{Matching of Cases and Controls}

Cases were matched to controls using propensity score matching to ensure balanced pre-index date patient characteristics between both cohorts. Patient characteristics assessed during the 12-month pre-index period were used in the propensity score matching. First, the cohorts were stratified by age group ( $<65$ years and $\geq 65$ years as of the index date) and the index year. Second, within each stratum, a logistic regression model was fitted to estimate the propensity of experiencing an upper GI event based on the pre-index patient characteristics. The pre-index patient characteristics that were included in the model were age group; type of insurance (health maintenance organization [HMO], point of service [POS], preferred provider organization [PPO], and other); presence of pre-index fracture (vertebral [lumbar and dorsal]), hip [femur neck], and other OP-related fractures); Charlson Comorbidity Index (CCI) score; ${ }^{24}$ total number of pre-index hospitalizations; and total pre-index health care costs. Concomitant use of the following medications was ascertained: gastro-protective agents, glucocorticoids, nonsteroidal anti-inflammatory drugs (NSAID), and estrogen. Finally, using the 1-to-1 nearest-neighbor matching, cases were then matched to controls based on the propensity scores estimated by the logistic regression model. Cases were not matched if there were no controls with an estimated propensity score within the allowable range (caliper: 0.2 standard deviations of the propensity score) of the cases. Cases that were not matched to controls were excluded from the analysis.

\section{Baseline Characteristics of Patients}

The following demographic and clinical characteristics of patients were captured during the baseline period ( 1 year preindex date): (a) age on the index date categorized into 4 groups (55-64, 65-74, 75-84, and $\geq 85$ years); (b) type of insurance (HMO, PPO, POS, or other); (c) CCI score (0, 1, 2, $\geq 3$ ); (d) baseline fracture (any, vertebral, hip, or other); (e) baseline use of gastroprotective agents (proton pump inhibitor, H2-antagonist, or cytoprotectant), NSAIDs, glucocorticoids, and estrogen; and (f) baseline comorbid conditions.

\section{Outcomes}

Health Care Resource Utilization. Total health care resource utilization was categorized as medical or pharmacy utilization. Medical utilization included all services conducted in the inpatient and outpatient settings and was categorized into inpatient, outpatient, emergency room (ER), and other, based on the place at which the service was performed. For instance, services performed in inpatient hospital, inpatient psychiatric facilities, and comprehensive inpatient rehabilitation facilities were classified as inpatient claims. All visits in the same category in a single day were considered as a single service use. For inpatient and ER episodes, services performed on consecutive days were combined into 1 episode to ensure that 2 distinct episodes were at least 1 day apart. We also examined 
post-index medication use (gastroprotective agents, NSAIDs, glucocorticoids, and estrogen).

Medical Utilization. Medical utilization was analyzed in 2 domains in this study: (1) all-cause medical utilization, which included medical services related to any medical cause, and (2) OP-related medical utilization, which included only services with a primary or secondary diagnosis of osteoporosis (ICD9-CM 733.0x code). We calculated the health care resource utilization rates as the percentage of patients utilizing each type of service. The total number of hospitalizations, outpatient visits, ER visits, and other medical resource utilization were also determined for each patient.

\section{Statistical Analyses}

Descriptive statistics were examined by cohort. Categorical variables were described by their frequency and continuous variables by their mean and standard deviation. Pre-index baseline characteristics were compared between cases and controls using the Wilcoxon rank sum test for continuous variables and chi-square test for categorical variables. Matchadjusted analysis was used to examine the association between upper-GI events and all-cause health care resource utilization and OP-related health care resource utilization during the 6-month post-index period. Differences in all-cause and OP-related health care resource utilization rates between the 2 cohorts (cases and controls) were assessed using McNemar's tests, whereas differences in average number of health care resource utilization were assessed by Wilcoxon signed rank tests. All analyses were conducted using SAS version 9.3 (SAS Institute, Cary, NC).

\section{Results}

\section{Study Population and Patient Baseline Characteristics}

Of the 680,069 women who initiated oral OP therapy, 62,863 patients met the study inclusion criteria (Figure 2). The majority of patients ( $n=340,855)$ were excluded for lack of continuous enrollment 1 year before and 10 months after initiation of OP treatment. The rate of upper GI events was $7.6 \%$ within 4 months among patients initiating BIS in the studied population. A total of 4,751 patients matched the case definition, and 4,739 of these patients were successfully matched 1:1 with control patients; 12 cases could not be matched within the allowable range and were excluded. Among the matched case patients, the mean (median) time to the first upper GI event was 54.7 (52) days.

The baseline characteristics of the patients are presented in Table 1. For both cases and controls, mean age was 65 years, and $63.3 \%$ of patients were aged 55-64 years. Mean CCI score was similar for cases (0.7) and controls (0.7), and $59.6 \%$ of patients had a CCI score of 0 . A total of 228 cases and 227 controls (4.8\%) experienced 1 or more fractures during the baseline period. The most common concomitant medications were NSAIDs prescribed for $31.9 \%$ of patients, followed by estrogen (22.6\%) and gastroprotective agents (21.3\%). The most frequently diagnosed comorbid conditions were hypertension (45.8\%), OP (45.3\%), osteopenia (38.5\%), musculoskeletal pain (34.0\%), and menopause/menopausal symptoms (29.7\%). No differences in distribution of patient baseline characteristics were observed between matched cases and controls.

\section{Health Care Resource Utilization}

Six-month resource utilization rates by cohort are presented in Table 2. Patients with a posttreatment upper GI event (cases) had a significantly higher rate of all-cause resource utilization for all service types (i.e., outpatient, inpatient, ER, and other medical services) compared with patients without posttreatment upper GI events (controls). For example, 20.2\% of the cases used inpatient services for any cause compared with $6.4 \%$ of the controls (odds ratio $[\mathrm{OR}]=3.7,95 \%$ confidence interval $[\mathrm{CI}]=3.4-4.6$ ). Similarly, when only OP-related health care resource utilization was examined, a significantly higher percentage of cases utilized any type of resource compared with the controls (outpatient: $24.6 \%$ vs. $18.2 \%$ [OR $=1.5,95 \%$ $\mathrm{CI}=1.3-1.6]$; inpatient: $3.4 \%$ vs. $1.0 \%[\mathrm{OR}=3.5,95 \% \mathrm{CI}=2.7-$ 5.2]; ER: $0.7 \%$ vs. $0.4 \%[\mathrm{OR}=1.9,95 \% \mathrm{CI}=1.1-3.5]$ ). A higher percentage of cases also used gastroprotective agents compared with controls (34.2\% vs. $16.6 \%$; $O R=2.6,95 \% C I=3.3-4.2]$ ).

\section{Average Number of Health Care Resource Use}

Table 3 displays the average number of health care resource use within 6 months after index date for both cohorts. Cases had a higher number of episodes of all-cause health care service utilization compared with the controls (outpatient: 8.77 vs. 5.80; inpatient: 0.32 vs. 0.09 ; ER: 0.30 vs. 0.22 ; all $P<0.001$ ). The same pattern of significantly higher service utilization was evident for OP-related health care resource use.

\section{Discussion}

This study assessed the association between upper GI events and all-cause and OP-related health care resource utilization among osteoporotic patients initiating oral BIS in a large U.S. managed care population. We excluded patients with a prior history of GI events to avoid the potential bias of preexisting GI events and employed propensity score matching for a more robust evaluation of the contribution of upper GI events to health care utilization. Our results suggest that patients with an upper GI event have a significantly higher rate of all-cause and OP-related resource utilization for all service categories, including inpatient and ER services, compared with patients without GI events after treatment. 


\section{FIGURE 2 Study Sample Selection}

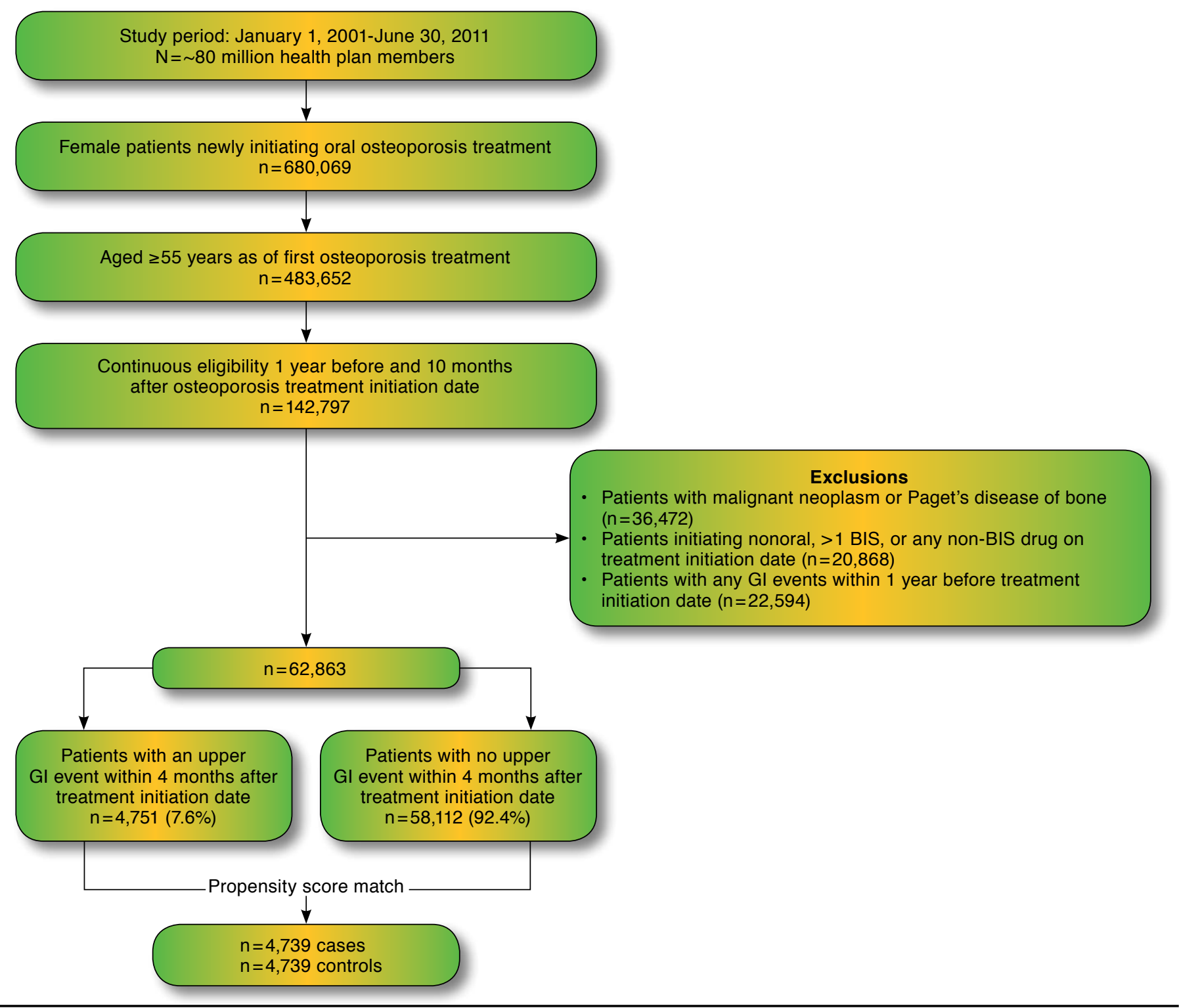

BIS= bisphosphonate; GI= gastrointestinal.

In our sample, $7.6 \%$ of patients initiating oral BIS therapy experienced an upper GI event after treatment. This rate is lower than results reported in previous, smaller scale observational studies showing that $10 \%-33 \%$ of patients experienced an upper GI or any GI event during oral BIS therapy. ${ }^{13-15}$ In our study, only upper GI events that resulted in medical health care utilization were considered, whereas the previous studies were based on self-reported GI symptoms that may or may not have resulted in medical resource utilization. Further, we excluded patients with prior GI events to minimize the potential impact of preexisting conditions on the GI event rate, while the earlier studies did not. Nevertheless, $21 \%$ of patients overall were using prescription gastroprotective agents during the baseline period, suggesting that GI symptoms are relatively common in this population.

In this study, the occurrence of upper GI events after initiation of BIS treatment may be associated with use of BIS or background conditions, which commonly exist in elderly osteoporotic women. 


\begin{tabular}{|c|c|c|c|c|c|c|c|}
\hline \multirow[b]{2}{*}{ Variable } & \multirow{2}{*}{$\begin{array}{c}\begin{array}{c}\text { Patients with } \\
\text { Upper GI Event } \\
\text { After Treatment } \\
(\mathrm{n}=4,739)\end{array} \\
\text { Mean (SD) } \\
\end{array}$} & \multirow[t]{2}{*}{$\begin{array}{c}\text { Patients with } \\
\text { No Upper GI } \\
\text { Event After } \\
\text { Treatment } \\
(\mathrm{n}=4,739) \\
\text { Mean (SD) } \\
\end{array}$} & \multirow[b]{2}{*}{$P$ Value $^{\mathrm{a}}$} & \multirow[b]{2}{*}{ Variable } & \multirow{2}{*}{\begin{tabular}{|c|}
$\begin{array}{c}\text { Patients with } \\
\text { Upper GI Event } \\
\text { After Treatment } \\
(\mathrm{n}=4,739)\end{array}$ \\
$\mathbf{n}(\%)$ \\
\end{tabular}} & \multirow[t]{2}{*}{$\begin{array}{c}\text { Patients with } \\
\text { No Upper GI } \\
\text { Event After } \\
\text { Treatment } \\
(\mathrm{n}=4,739) \\
\mathbf{n}(\%)\end{array}$} & \multirow[b]{2}{*}{$P$ Value $^{a}$} \\
\hline & & & & & & & \\
\hline Age (years) & $64.7(8.9)$ & $64.7(8.8)$ & 0.686 & Comorbidities & & & \\
\hline \multirow[t]{2}{*}{ Charlson comorbidity score } & $0.7(1.1)$ & $0.7(1.1)$ & 0.947 & Osteoporosis & $2,144 \quad(45.2)$ & $2,150 \quad(45.4)$ & 0.902 \\
\hline & n (\%) & n (\%) & & Hypertension & $2,183(46.1)$ & $2,154(45.5)$ & 0.550 \\
\hline Age group (years) & & & 0.458 & Osteopenia & $1,839(38.8)$ & $1,806(38.1)$ & 0.486 \\
\hline $55-64$ & $3,002 \quad(63.3)$ & $2,998(63.3)$ & & Musculoskeletal pain & $1,595 \quad(33.7)$ & $1,630(34.4)$ & 0.448 \\
\hline $65-74$ & $943(19.9)$ & $941 \quad(19.9)$ & & Respiratory diseases & $1,414 \quad(29.8)$ & $1,436(30.3)$ & 0.622 \\
\hline $75-84$ & $610(12.9)$ & $641(13.5)$ & & Menopause and & $1,404 \quad(29.6)$ & $1,411 \quad(29.8)$ & 0.875 \\
\hline 85 or older & $184 \quad(3.9)$ & $159 \quad(3.4)$ & & menopausal symptoms & & & \\
\hline Charlson comorbidity score & & & 0.828 & Dementia, depression, & 928 (19.6) & $895(18.9)$ & 0.390 \\
\hline 0 & $2,844(60.0)$ & $2,806(59.2)$ & & anxiety, sleep disorders & & & \\
\hline 1 & $1,212 \quad(25.6)$ & $1,250 \quad(26.4)$ & & Hypothyroidism & $870(18.4)$ & $878(18.5)$ & 0.832 \\
\hline 2 & $380 \quad(8.0)$ & $384 \quad(8.1)$ & & Diabetes & $575(12.1)$ & $575(12.1)$ & 1.000 \\
\hline 3 or more & $303 \quad(6.4)$ & $299 \quad(6.3)$ & & Cardiovascular diseases & $487(10.3)$ & $495 \quad(10.4)$ & 0.787 \\
\hline Health plan type & & & 0.803 & Cerebrovascular diseases & $327 \quad(6.9)$ & $310 \quad(6.5)$ & 0.486 \\
\hline $\mathrm{HMO}$ & $1,237 \quad(26.1)$ & $1,210 \quad(25.5)$ & & Nutritional disorders & $183 \quad(3.9)$ & $190 \quad(4.0)$ & 0.712 \\
\hline POS & $\begin{array}{ll}1,859 & (39.2) \\
\end{array}$ & $\begin{aligned} 1,857 & (39.2) \\
710 & (1500\end{aligned}$ & & Kidney diseases & $153 \quad(3.2)$ & $144 \quad(3.0)$ & 0.596 \\
\hline$\frac{\mathrm{PPO}}{\text { Other }}$ & $\begin{array}{ll}679 & (14.3) \\
964 & (203)\end{array}$ & $\begin{array}{ll}710 & (15.0) \\
962 & (203)\end{array}$ & & Obesity & $131 \quad(2.8)$ & $138 \quad(2.9)$ & 0.665 \\
\hline \multicolumn{4}{|l|}{ Baseline fracture ${ }^{b}$} & $\begin{array}{l}\text { Indication of decreased } \\
\text { mobility }\end{array}$ & $118 \quad(2.5)$ & $111 \quad(2.3)$ & 0.640 \\
\hline Any & $228 \quad(4.8)$ & $\begin{array}{rr}227 \quad(4.8) \\
77\end{array}$ & $\frac{0.962}{0.526}$ & Hyperthyroidism & $98 \quad(2.1)$ & $104 \quad(2.2)$ & 0.670 \\
\hline $\begin{array}{l}\text { Vertebral (dorsal or lumbar) } \\
\text { Hin }\end{array}$ & $\begin{array}{ll}85 & (1.8) \\
38 & (0.8)\end{array}$ & $\begin{array}{ll}77 & (1.6) \\
37 & (08)\end{array}$ & $\begin{array}{l}0.526 \\
0.908\end{array}$ & Vitamin D deficiency & $88 \quad(1.9)$ & $88 \quad(1.9)$ & 1.000 \\
\hline $\begin{array}{l}\text { Hip } \\
\text { Other }\end{array}$ & $\begin{array}{rr}38 & (0.8) \\
143 & (3.0) \\
\end{array}$ & $\begin{array}{rr}37 & (0.8) \\
142 & (3.0) \\
\end{array}$ & $\begin{array}{l}0.908 \\
0.952 \\
\end{array}$ & $\begin{array}{l}\text { Inflammatory bowel } \\
\text { diseases }\end{array}$ & $38 \quad(0.8)$ & $34 \quad(0.7)$ & 0.636 \\
\hline \multicolumn{4}{|l|}{ Baseline medication use } & Hyperparathyroid & $29 \quad(0.6)$ & $26 \quad(0.5)$ & 0.685 \\
\hline NSAIDs & $1,506 \quad(31.8)$ & $1,515(32.0)$ & 0.843 & Alzheimer's disease & $30 \quad(0.6)$ & $21 \quad(0.4)$ & 0.206 \\
\hline $\begin{array}{l}\text { Estrogens } \\
\text { Gastroprotective agents }{ }^{c}\end{array}$ & $\begin{array}{ll}1,049 & (22.1) \\
1,027 & (21.7)\end{array}$ & $\begin{array}{r}1,089(23.0) \\
995(21.0)\end{array}$ & $\begin{array}{l}0.320 \\
0.422\end{array}$ & Arthritis & $30 \quad(0.6)$ & $21 \quad(0.4)$ & 0.206 \\
\hline $\begin{array}{l}\text { Gastroprotective agents } \\
\text { Proton pump inhibitors }\end{array}$ & $840 \quad(17.7)$ & $731 \quad(15.4)$ & 0.003 & Parkinson's disease & $28 \quad(0.6)$ & $26 \quad(0.5)$ & 0.785 \\
\hline $\mathrm{H} 2$ antagonists & $190 \quad(4.0)$ & $240 \quad(5.1)$ & 0.014 & Alcohol use disorders & $18 \quad(0.4)$ & $15 \quad(0.3)$ & 0.601 \\
\hline Cytoprotectants & $51 \quad(1.1)$ & $73 \quad(1.5)$ & 0.047 & Celiac disease & $8 \quad(0.2)$ & $8 \quad(0.2)$ & 1.000 \\
\hline Glucocorticoids & $964(20.3)$ & $928 \quad(19.6)$ & 0.355 & Bulimia or anorexia & $9 \quad(0.2)$ & $6 \quad(0.1)$ & 0.438 \\
\hline
\end{tabular}

aWilcoxon rank sum test (continuous variables) and chi-square test (categorical variables) were used for comparison of cohorts. P values in bold indicate statistical significance. bSome patients had $>1$ fracture, so the sum of hip, vertebral, and other fracture may not add up to any fracture.

cSome patients had prescriptions for $>1$ gastroprotective agent.

$G I=$ gastrointestinal; $H M O=$ health maintenance organization; NSAID = nonsteroidal anti-inflammatory drug; POS= point of service; $P P O=$ preferred provider organization; $S D=$ standard deviation.

The occurrence of upper GI events was a risk factor for all-cause and OP-related health care utilization among women initiating BIS, regardless of whether the upper GI events were caused by use of BIS, use of other medications, or concomitant medical conditions.

Although upper GI events with relatively less severity, such as abdominal pains, may not lead to hospitalization or other health care resource utilization, patients who experienced any upper GI events after BIS treatment initiation had significantly greater odds of all-cause health care utilization, with the most pronounced differences evident for outpatient services (18.3 higher odds) and inpatient stays (3.7 higher odds), compared with control patients. OP-related service utilization followed a similar pattern of significantly higher use for all service categories among patients with upper GI events. At baseline, concurrent use of gastroprotective agents was similar between cases and controls, $21.7 \%$ and $21.0 \%$, respectively. After initiating oral BIS therapy, the percentage of case patients taking gastroprotective agents increased considerably from baseline (34.2\%), while usage in the control group declined from baseline (16.6\%). The most common gastroprotective agents used were proton pump inhibitors and $\mathrm{H} 2$ receptor antagonists; these agents are indicated for prevention and treatment of gastric and duodenal ulcers and gastroesophageal reflux disease. 


\begin{tabular}{|c|c|c|c|c|c|c|c|}
\hline \multirow[b]{2}{*}{ Resource } & \multicolumn{2}{|c|}{$\begin{array}{c}\text { Patients with Upper } \\
\text { GI Event After } \\
\text { Treatment } \\
(\mathrm{n}=4,739) \\
\end{array}$} & \multicolumn{2}{|c|}{$\begin{array}{c}\text { Patients with No } \\
\text { Upper GI Event After } \\
\text { Treatment } \\
(\mathrm{n}=4,739)\end{array}$} & \multirow[b]{2}{*}{ Odds Ratio } & \multirow[b]{2}{*}{$95 \%$ CI } & \multirow[b]{2}{*}{$P$ Value } \\
\hline & & & & & & & \\
\hline \multicolumn{8}{|l|}{ All-cause services } \\
\hline Outpatient & 4,704 & $(99.3)$ & 4,163 & $(87.8)$ & 18.3 & $(13.8-29.2)$ & $<0.0001$ \\
\hline Inpatient & 955 & $(20.2)$ & 302 & $(6.4)$ & 3.7 & $(3.4-4.6)$ & $<0.0001$ \\
\hline Emergency room & 594 & $(12.5)$ & 351 & $(7.4)$ & 1.8 & $(1.6-2.1)$ & $<0.0001$ \\
\hline Other & 3,081 & $(65.0)$ & 2,276 & $(48.0)$ & 2.0 & $(1.9-2.2)$ & $<0.0001$ \\
\hline \multicolumn{8}{|l|}{ OP-related services } \\
\hline Outpatient & 1,168 & $(24.6)$ & 863 & $(18.2)$ & 1.5 & $(1.3-1.6)$ & $<0.0001$ \\
\hline Inpatient & 162 & (3.4) & 47 & $(1.0)$ & 3.5 & $(2.7-5.2)$ & $<0.0001$ \\
\hline Emergency room & 35 & $(0.7)$ & 18 & $(0.4)$ & 1.9 & $(1.1-3.5)$ & 0.020 \\
\hline Other & 229 & $(4.8)$ & 173 & $(3.7)$ & 1.3 & $(1.1-1.7)$ & 0.004 \\
\hline \multicolumn{8}{|l|}{ Post-index medication use } \\
\hline Gastroprotective agents & 1,623 & $(34.2)$ & 786 & $(16.6)$ & 2.6 & $(3.3-4.2)$ & $<0.0001$ \\
\hline Proton pump inhibitors & 1,449 & $(30.6)$ & 609 & $(12.9)$ & 3.0 & $(3.6-4.7)$ & $<0.0001$ \\
\hline $\mathrm{H} 2$ antagonists & 209 & $(4.4)$ & 165 & $(3.5)$ & 1.3 & $(1.1-1.7)$ & 0.014 \\
\hline Cytoprotectants & 86 & (1.8) & 50 & $(1.1)$ & 1.7 & $(1.3-2.6)$ & 0.001 \\
\hline NSAIDs & 1,144 & $(24.1)$ & 1,082 & $(22.8)$ & 1.1 & $(1.0-1.2)$ & 0.121 \\
\hline Glucocortocoids & 760 & $(16.0)$ & 672 & $(14.2)$ & 1.2 & $(1.0-1.3)$ & 0.010 \\
\hline Estrogens & 693 & $(14.6)$ & 733 & $(15.5)$ & 0.9 & $(0.8-1.1)$ & 0.227 \\
\hline
\end{tabular}

The findings from our study aid in understanding the health care resource utilization burden associated with upper GI events among patients newly initiating oral BIS therapy. Although this study cannot imply a causal relationship between upper GI events and BIS use as per study design, health care practitioners must remain cognizant of upper GI events among patients on OP medications, should routinely ask about preexisting upper GI disorders and concurrent medication history, and should consider alternate treatments for patients with upper GI events. Furthermore, the burden associated with upper GI events can have implications for managed care health plans from a medical resource use and pharmacy perspective. A recent study reported an association between GI events following oral BIS initiation and greater risk of discontinuation or switching to alternate therapy. ${ }^{25}$ Patients discontinuing therapy due to GI intolerance will require prompt approval of alternative $\mathrm{OP}$ treatment to reduce fracture risk and the consequential medical resource burden.

\section{Limitations}

There are several limitations to our study, and the results should be interpreted in this context. Our results are based on administrative claims data, which are subject to coding errors and missing codes. Claims data do not provide insight into the possible cause of upper GI events, such as oral BIS dosing schedule, compliance with dosing instructions and medication adherence, or something unrelated to osteoporosis medications. We cannot infer that oral BIS initiation causes upper GI events. However, significant comorbid GI disease prior to initiating oral BIS therapy is unlikely to be a confounding factor because patients with any GI events in the year prior to initiating oral BIS therapy were excluded. Nevertheless, the upper GI events that distinguished cases from controls are based only on those events that resulted in medical service utilization and were coded as such. Thus, less severe GI events that did not result in a medical encounter may have been present in both cohorts prior to and during the study, and these events would not have been captured. Although we employed propensity scores to match case and control patients for clinical and demographic characteristics, there may have been other, unmeasured factors that potentially influenced results. For example, bone mineral density tests results (e.g., T-scores) were not available in the claims database. Finally, our results are based on patients with commercial insurance in a stable, managed care setting and may not be generalizable to patients with other forms of insurance or the uninsured. 


\begin{tabular}{|c|c|c|c|c|}
\hline TABL & \multicolumn{4}{|c|}{$\begin{array}{l}\text { Number of Health Care Resource } \\
\text { Utilizations Per Patient by Cohort } \\
\text { During 6-Month Study Period }\end{array}$} \\
\hline \multirow[b]{2}{*}{ Resource } & \multirow{2}{*}{\begin{tabular}{|c|}
$\begin{array}{c}\text { Patients with } \\
\text { Upper GI Event } \\
\text { After Treatment } \\
(\mathrm{n}=4,739)\end{array}$ \\
A: Mean (SD)
\end{tabular}} & \multirow{2}{*}{$\begin{array}{c}\text { Patients with No } \\
\text { Upper GI Event } \\
\text { After Treatment } \\
(\mathrm{n}=4,739) \\
\text { B: Mean (SD) }\end{array}$} & \multirow{2}{*}{$\begin{array}{c}\text { Difference } \\
\text { A-B }\end{array}$} & \multirow[b]{2}{*}{$P$ Value ${ }^{a}$} \\
\hline & & & & \\
\hline \multicolumn{5}{|c|}{ All-cause services } \\
\hline Outpatient & $8.77 \quad(8.6)$ & $5.80 \quad(7.7)$ & 2.975 & $<0.0001$ \\
\hline Inpatient & $0.32 \quad(0.9)$ & $0.09 \quad(0.4)$ & 0.224 & $<0.0001$ \\
\hline $\begin{array}{l}\text { Emergency } \\
\text { room }\end{array}$ & $0.30 \quad(1.3)$ & $0.22 \quad(1.3)$ & 0.079 & $<0.0001$ \\
\hline Other & $2.34 \quad(5.9)$ & $1.71 \quad(7.5)$ & 0.622 & $<0.0001$ \\
\hline \multicolumn{5}{|c|}{ OP-related services } \\
\hline Outpatient & $0.45 \quad(1.4)$ & $0.32 \quad(1.2)$ & 0.131 & $<0.0001$ \\
\hline Inpatient & $0.04 \quad(0.3)$ & $0.01 \quad(0.1)$ & 0.030 & $<0.0001$ \\
\hline $\begin{array}{l}\text { Emergency } \\
\text { room }\end{array}$ & $0.01 \quad(0.1)$ & $0.00 \quad(0.1)$ & 0.004 & 0.035 \\
\hline Other & $0.13 \quad(1.5)$ & $0.09 \quad(1.1)$ & 0.046 & 0.001 \\
\hline
\end{tabular}

\section{Conclusions}

The rate of upper GI events was 7.6\% within 4 months among patients initiating BIS based on this study using claims data from a U.S. commercial plan. However, this study design reflects correlational relationships only and does not ascribe causality of upper GI symptoms and use of BIS. Study results show that patients experiencing an upper GI diagnosis after treatment initiation with BIS were 1.5 times as likely to use outpatient OP-related services, 3.5 times as likely to use inpatient OP-related services, and 1.9 times as likely to use OP-related ER services, compared with patients without an upper GI diagnosis after treatment initiation with BIS. Results from this study suggest that upper GI events may pose an incremental health care resource burden among patients with OP.

\section{Authors}

ANKITA MODI, PhD, is Director; SHIVA G. SAJJAN, PhD, is Director; and XIAOQIN YANG, PhD, is Associate Director, Center for Observational and Real-World Evidence, Merck E Co., Kenilworth, New Jersey. DEBORAH T. GOLD, PhD, is Associate Professor, Duke University Medical Center, Durham, North Carolina, and CHUN-PO STEVE FAN, PhD, is Director, Asclepius JT, Brooklyn, New York.

AUTHOR CORRESPONDENCE: Ankita Modi, PhD, Merck \& Co., 600 Corporate Dr., Lebanon, NJ 08833. Tel.: 908.236.4563;

Fax: 908.236.4697; E-mail: ankita.modi@merck.com.

\section{DISCLOSURES}

This study was sponsored by Merck \& Co. Modi, Yang, and Sajjan are employees of Merck \& Co., Kenilworth, NJ. Gold is a consultant to Merck \& Co., and Fan served as a paid consultant in connection with this study and development of the manuscript.

Study concept and design were created by Modi, with assistance from the other authors. Sajjan, Gold, and Fan collected the data, and data interpretation was performed by Modi and Sajjan, with assistance from the other authors. The manuscript was written by Sajjan, Yang, Modi, and Gold, with assistance from Fan, and revised by Modi, Yang, and Fan, with assistance from Gold and Sajjan.

\section{ACKNOWLEDGMENTS}

Medical writing support was provided by Optum (Eden Prairie, MN) and was funded by Merck \& Co.

\section{REFERENCES}

1. Bartholow M. Top 200 drugs of 2012. Pharmacy Times. July 17, 2013 Available at: http://www.pharmacytimes.com/publications/issue/2013/ July2013/Top-200-Drugs-of-2012. Accessed August 7, 2015.

2. Harris ST, Watts NB, Genant HK, et al. Effects of risedronate treatment on vertebral and nonvertebral fractures in women with postmenopausal osteoporosis: a randomized controlled trial. Vertebral Efficacy With Risedronate Therapy (VERT) Study Group. JAMA. 1999;282(14):1344-52. Available at: http://jama.jamanetwork.com/article.aspx?articleid=191987. Accessed August 7, 2015.

3. Black DM, Cummings SR, Karpf DB, et al. Randomised trial of effect of alendronate on risk of fracture in women with existing vertebral fractures Fracture Intervention Trial Research Group. Lancet. 1996;348(9041):1535-41. Available at: http://www.thelancet.com/pdfs/journals/lancet/ PIIS0140673696070882.pdf. Accessed August 7, 2015.

4. Cummings SR, Black DM, Thompson DE, et al. Effect of alendronate on risk of fracture in women with low bone density but without vertebral fractures: results from the Fracture Intervention Trial. JAMA. 1998;280(24): 2077-82. Available at: http://jama.jamanetwork.com/article. aspx?articleid=188299. Accessed August 7, 2015.

5. Jansen JP, Bergman GJ, Huels J, Olson M. The efficacy of bisphosphonates in the prevention of vertebral, hip, and nonvertebral-nonhip fractures in osteoporosis: a network meta-analysis. Semin Arthritis Rheum. 2011;40(4):275-84.el-2. Available at: http://www.researchgate.net/publication/46190880_The_efficacy_of_bisphosphonates_in_the_prevention_of_ vertebral_hip_and_nonvertebral-nonhip_fractures_in_osteoporosis_a_ network_meta-analysis._Semin_Arthritis_Rheum_40\%28275284\%29e271-e272. Accessed August 7, 2015.

6. MacLean C, Newberry S, Maglione M, et al. Systematic review: comparative effectiveness of treatments to prevent fractures in men and women with low bone density or osteoporosis. Ann Intern Med. 2008;148(3):197-213. Available at: http://annals.org/article.aspx?articleid=739219. Accessed August 7, 2015.

7. Chesnut IC, Skag A, Christiansen C, et al. Effects of oral ibandronate administered daily or intermittently on fracture risk in postmenopausal osteoporosis. J Bone Miner Res. 2004;19(8):1241-49.

8. Woo C, Gao G, Wade S, Hochberg MC. Gastrointestinal side effects in postmenopausal women using osteoporosis therapy: 1-year findings in the POSSIBLE US study. Curr Med Res Opin. 2010;26(4):1003-09.

9. Reginster JY, Rabenda V. Patient preference in the management of postmenopausal osteoporosis with bisphosphonates. Clin Interv Aging. 2006;1(4):415-23. Available at: http://www.ncbi.nlm.nih.gov/pmc/articles/ PMC2699650/. Accessed August 7, 2015.

10. de Groen PC, Lubbe DF, Hirsch LJ, et al. Esophagitis associated with the use of alendronate. N Engl J Med. 1996;335(14):1016-21. Available at: http://www. nejm.org/doi/full/10.1056/NEJM199610033351403. Accessed August 7, 2015. 


\section{Association Between Gastrointestinal Events and Health Care Resource Utilization Among Patients with Osteoporosis: Analysis of a U.S. Managed Care Population}

11. Lanza FL, Hunt RH, Thomson AB, Provenza JM, Blank MA. Endoscopic comparison of esophageal and gastroduodenal effects of risedronate and alendronate in postmenopausal women. Gastroenterology. 2000;119(3):631-38.

12. McHorney CA, Schousboe JT, Cline RR, Weiss TW. The impact of osteoporosis medication beliefs and side-effect experiences on non-adherence to oral bisphosphonates. Curr Med Res Opin. 2007;23(12):3137-52

13. Ettinger J, Pressman A, Schein J, Chan J, Silver P, Connolly N. Alendronate use among 812 women: prevalence, complaints, noncompliance with patient instructions, and discontinuation. J Managed Care Pharm. 1998;4(5):488-92. Available at: http://www.amcp.org/WorkArea/ DownloadAsset.aspx?id=6025

14. Hamilton B, McCoy K, Taggart H. Tolerability and compliance with risedronate in clinical practice. Osteoporos Int. 2003;14(3):259-262.

15. Turbi C, Herrero-Beaumont G, Acebes JC, et al. Compliance and satisfaction with raloxifene versus alendronate for the treatment of postmenopausal osteoporosis in clinical practice: an open-label, prospective, nonrandomized, observational study. Clin Ther. 2004;26(2):245-56.

16. Huybrechts KF, Ishak KJ, Caro JJ. Assessment of compliance with osteoporosis treatment and its consequences in a managed care population. Bone. 2006;38(6):922-28

17. Siris ES, Harris ST, Rosen CJ, et al. Adherence to bisphosphonate therapy and fracture rates in osteoporotic women: relationship to vertebral and nonvertebral fractures from 2 US claims databases. Mayo Clin Proc. 2006;81(8):1013-22.

18. Rabenda V, Mertens R, Fabri V, et al. Adherence to bisphosphonates therapy and hip fracture risk in osteoporotic women. Osteoporos Int. 2008;19(6):811-18.
19. Patrick AR, Brookhart MA, Losina E, et al. The complex relation between bisphosphonate adherence and fracture reduction. J Clin Endocrinol Metab. 2010;95(7):3251-59. Available at: http://www.ncbi.nlm.nih.gov/pmc/articles/ PMC2928897/. Accessed August 7, 2015.

20. Gold DT, Martin BC, Frytak JR, Amonkar MM, Cosman F. A claims database analysis of persistence with alendronate therapy and fracture risk in post-menopausal women with osteoporosis. Curr Med Res Opin. 2007;23(3):585-94.

21. Halpern R, Becker L, Iqbal SU, Kazis LE, Macarios D, Badamgarav E. The association of adherence to osteoporosis therapies with fracture, all-cause medical costs, and all-cause hospitalizations: a retrospective claims analysis of female health plan enrollees with osteoporosis. J Manag Care Pharm. 2011;17(1):25-39. Available at: http://www.amcp.org/data/jmcp/25-39.pdf.

22. Health Insurance Portability and Accountability Act of 1996. Pub.L. 104-191, 110 Stat. 1936. August 21, 1996. Available at: http://www.hhs gov/ocr/privacy/hipaa/administrative/statute/hipaastatutepdf.pdf. Accessed August 7, 2015.

23. Bauer DC, Black D, Ensrud K, et al. Upper gastrointestinal tract safety profile of alendronate: the fracture intervention trial. Arch Intern Med. 2000;160(4):517-25. Available at: http://archinte.jamanetwork.com/article. aspx?articleid=485235. Accessed August 7, 2015.

24. Quan H, Sundararajan V, Halfon P, et al. Coding algorithms for defining comorbidities in ICD-9-CM and ICD-10 administrative data. Med Care 2005;43(11):1130-39.

25. Modi A, Siris ES, Yang X, Fan CP, Sajjan S. Association between gastrointestinal events and persisitence with osteoporosis therapy: analysis of administrative claims of a U.S. managed care population. J Manag Care Spec Pharm. 2015;21(6):499-506. Available at: http://www.amcp.org/WorkArea/ DownloadAsset.aspx?id=19648. 


\section{Association Between Gastrointestinal Events and Health Care Resource Utilization Among Patients with Osteoporosis: Analysis of a U.S. Managed Care Population}

\section{APPENDIX ICD-9-CM and CPT Codes for Identification of Gastrointestinal Events}

ICD-9-CM Code

$456.0 \mathrm{x}$

$456.1 \mathrm{x}$

$530.0 \mathrm{x}$

$530.1 \mathrm{x}$

$530.2 \mathrm{x}$

$530.3 \mathrm{x}$

$530.4 \mathrm{x}$

$530.5 \mathrm{x}$

$530.6 \mathrm{x}$

$530.7 \mathrm{x}$

530.81

530.82

530.84

530.89

$531 . x x$

$531.0 \mathrm{x}$

$531.1 \mathrm{x}$

$531.2 \mathrm{x}$

$531.3 \mathrm{x}$

$531.4 \mathrm{x}$

$531.5 \mathrm{x}$

$531.6 \mathrm{x}$

$531.7 \mathrm{x}$

$531.9 \mathrm{x}$

532.xx

$532.0 \mathrm{x}$

$532.1 \mathrm{x}$

$532.2 \mathrm{x}$

$532.3 \mathrm{x}$

$532.4 \mathrm{x}$

$532.5 \mathrm{x}$

$532.6 \mathrm{x}$

$532.7 \mathrm{x}$

$532.9 \mathrm{x}$

533.xx

$533.0 \mathrm{x}$

$533.1 \mathrm{x}$

$533.2 \mathrm{x}$

$533.3 \mathrm{x}$

$533.4 \mathrm{x}$

$533.5 \mathrm{x}$

$533.6 \mathrm{x}$

$533.7 \mathrm{x}$

$533.9 \mathrm{x}$

534.xx

$534.0 \mathrm{x}$

$534.1 \mathrm{x}$

$534.2 \mathrm{x}$

$534.3 \mathrm{x}$

$535.0 \mathrm{x}$

535.11

535.21

$535.4 \mathrm{x}$

$535.5 x$
Description

Esophageal varices with bleeding

Esophageal varices without mention of bleeding

Achalasia \& caridospasm

Esophagitis

Ulcer of esophagus

Stricture and stenosis of esophagus

Perforation of esophagus

Dyskinesia of esophagus

Diverticulum of esophagus, acquired

Gastroesophageal laceration-hemorrhage syndrome

Esophageal reflux (GERD)

Esophageal hemorrhage

Tracheoesophageal fistula

Other disorders of the esophagus

Gastric ulcer

Gastric ulcer acute with hemorrhage

Gastric ulcer acute with perforation

Gastric ulcer acute with hemorrhage and perforation

Gastric ulcer acute without mention of hemorrhage or perforation

Gastric ulcer chronic or unspecified with hemorrhage

Gastric ulcer chronic or unspecified with perforation

Gastric ulcer chronic or unspecified with hemorrhage and perforation

Gastric ulcer chronic without mention of hemorrhage or perforation

Gastric ulcer unspecified as acute or chronic, without mention of hemorrhage or perforation

Duodenal ulcer

Duodenal ulcer acute with hemorrhage

Duodenal ulcer acute with perforation

Duodenal ulcer acute with hemorrhage and perforation

Duodenal ulcer acute without mention of hemorrhage or perforation

Duodenal ulcer chronic or unspecified with hemorrhage

Duodenal ulcer chronic or unspecified with perforation

Duodenal ulcer chronic or unspecified with hemorrhage and perforation

Duodenal ulcer chronic without mention of hemorrhage or perforation

Duodenal ulcer unspecified as acute or chronic, without mention of hemorrhage or perforation

Peptic ulcer, site unspecified

Peptic ulcer, site unspecified acute with hemorrhage

Peptic ulcer, site unspecified acute with perforation

Peptic ulcer, site unspecified acute with hemorrhage and perforation

Peptic ulcer, site unspecified acute without mention of hemorrhage and perforation

Peptic ulcer, site unspecified chronic or unspecified with hemorrhage

Peptic ulcer, site unspecified chronic or unspecified with perforation

Peptic ulcer, site unspecified chronic or unspecified with hemorrhage and perforation

Peptic ulcer, site unspecified chronic without mention of hemorrhage or perforation

Peptic ulcer, site unspecified, unspecified as acute or chronic, without mention of hemorrhage or perforation

Gastrojejunal ulcer

Gastrojejunal ulcer acute with hemorrhage

Gastrojejunal ulcer acute with perforation

Gastrojejunal ulcer acute with hemorrhage and perforation

Gastrojejunal ulcer acute without mention of hemorrhage or perforation

Acute gastritis

Atrophic gastritis with hemorrhage

Gastric mucosal hypertrophy with hemorrhage

Gastritis NEC

Gastritis/duodenitis NOS
Any GI $\quad$ Upper GI

Event $^{\mathrm{a}} \quad$ Event $^{\mathrm{b}}$

$x$

$\mathrm{x}$

$\mathrm{x}$

$\mathrm{x}$

$\mathrm{x}$

$\mathrm{x}$

$\mathrm{x}$

$\mathrm{x}$

$\mathrm{x}$

$\mathrm{x}$

$\mathrm{x}$

$\mathrm{x}$

$\mathrm{x}$

$\mathrm{x}$

$\mathrm{x}$

$\mathrm{x}$

$\mathrm{x}$

$\mathrm{x}$

$\mathrm{x}$

$\mathrm{x}$

$\mathrm{x}$

$\mathrm{x}$

$\mathrm{x}$

$\mathrm{x}$

$\mathrm{x}$

$\mathrm{x}$

$\mathrm{x}$

$\mathrm{x}$

$\mathrm{x}$

$\mathrm{x}$

$\mathrm{x}$

$\mathrm{x}$

$\mathrm{x}$

$\mathrm{x}$

$\mathrm{x}$

$\mathrm{x}$

$\mathrm{x}$

$\mathrm{x}$

$\mathrm{x}$

$\mathrm{x}$

$\mathrm{x}$

$\mathrm{x}$

x

$\mathrm{x}$

X

x

$\mathrm{x}$

$\mathrm{x}$

$\mathrm{x}$

x

x .

$x$

$\mathrm{x}$

$\mathrm{x}$

$\mathrm{x}$

$\mathrm{x}$

$\mathrm{x}$

$\mathrm{x}$

$\mathrm{x}$

$\mathrm{x}$

$\mathrm{x}$

$\mathrm{x}$

$\mathrm{x}$
$\mathrm{x}$

$\mathrm{x}$

$\mathrm{x}$

$\mathrm{x}$
$\mathrm{x}$
$\mathrm{x}$

$\mathrm{x}$

$\mathrm{x}$

$\mathrm{x}$

$\mathrm{x}$

$\mathrm{x}$

X

$\mathrm{x}$

$\mathrm{x}$

$\mathrm{x}$




\section{Association Between Gastrointestinal Events and Health Care Resource Utilization Among Patients with Osteoporosis: Analysis of a U.S. Managed Care Population}

\section{APPENDIX ICD-9-CM and CPT Codes for Identification of Gastrointestinal Events (continued)}

\begin{tabular}{|c|c|c|c|}
\hline ICD-9-CM Code & Description & $\begin{array}{l}\text { Any GI } \\
\text { Event }^{\mathrm{a}}\end{array}$ & $\begin{array}{l}\text { Upper GI } \\
\text { Event }^{\mathrm{b}}\end{array}$ \\
\hline $535.6 x$ & Duodenitis & $\mathrm{x}$ & $\mathrm{x}$ \\
\hline $536.2 x$ & Persistent vomiting & $\mathrm{x}$ & $\mathrm{x}$ \\
\hline $536.8 \mathrm{x}$ & Dyspepsia and other specified disorders of function of stomach & $\mathrm{x}$ & $\mathrm{x}$ \\
\hline $536.9 x$ & Unspecified functional disorder of stomach & $\mathrm{x}$ & \\
\hline $537.4 x$ & Fistula of stomach or duodenum & $\mathrm{x}$ & \\
\hline $537.8 \mathrm{x}$ & Gastroduodenal disorders NEC & $\mathrm{x}$ & \\
\hline $537.9 x$ & Unspecified disorder of stomach and duodenum & $\mathrm{x}$ & \\
\hline 569.83 & Perforation of intestine & $\mathrm{x}$ & \\
\hline $578 . x x$ & GI hemorrhage & $\mathrm{x}$ & $\mathrm{x}$ \\
\hline $787.0 \mathrm{x}$ & Nausea and vomiting & $\mathrm{x}$ & $\mathrm{x}$ \\
\hline $787.1 x$ & Heartburn & $\mathrm{x}$ & $\mathrm{x}$ \\
\hline $787.2 \mathrm{x}$ & Dysphagia & $\mathrm{x}$ & $\mathrm{x}$ \\
\hline $789.0 x$ & Abdominal pain & $\mathrm{x}$ & $\mathrm{x}$ \\
\hline $792.1 x$ & Nonspecific abnormal findings in stool contents & $\mathrm{x}$ & \\
\hline $793.4 x$ & Nonspecific abnormal findings on radiological and other examination of gastrointestinal tract & $\mathrm{x}$ & \\
\hline CPT Code & Description & $\begin{array}{l}\text { Any GI } \\
\text { Event }^{\mathrm{a}}\end{array}$ & $\begin{array}{c}\text { Upper GI } \\
\text { Event }{ }^{\mathrm{b}}\end{array}$ \\
\hline 43200 & $\begin{array}{l}\text { Endoscopy, rigid or flexible; diagnostic, with or without collection of specimen(s) by brushing or washing } \\
\text { (separate procedure) }\end{array}$ & $\mathrm{x}$ & \\
\hline 43202 & $\begin{array}{l}\text { Esophagoscopy, rigid or flexible; diagnostic, with or without collection of specimen(s) by brushing or washing } \\
\text { (separate procedure) with biopsy, single or multiple }\end{array}$ & $\mathrm{x}$ & \\
\hline 43227 & $\begin{array}{l}\text { Esophagoscopy, rigid or flexible; diagnostic, with or without collection of specimen(s) by brushing or washing } \\
\text { (separate procedure) with control of bleeding, any method }\end{array}$ & $\mathrm{x}$ & \\
\hline 43235 & $\begin{array}{l}\text { Endoscopy, rigid or flexible; diagnostic, with or without collection of specimen(s) by brushing or washing } \\
\text { (separate procedure) }\end{array}$ & $\mathrm{x}$ & \\
\hline 43239 & $\begin{array}{l}\text { Upper GI endoscopy including esophagus, stomach, and either the duodenum and/or jejunum as appropriate; } \\
\text { diagnostic with or without collection of specimen(s) by brushing or washing (separate procedure) with biopsy, } \\
\text { single or multiple }\end{array}$ & $\mathrm{x}$ & \\
\hline 43255 & $\begin{array}{l}\text { Upper GI endoscopy including esophagus, stomach, and either the duodenum and/or jejunum as appropriate; } \\
\text { diagnostic with or without collection of specimen(s) by brushing or washing (separate procedure), with control } \\
\text { of bleeding, any method }\end{array}$ & $\mathrm{x}$ & \\
\hline 44602 & suture of small intestine (enterorrhaphy) for perforated ulcer & $\mathrm{x}$ & \\
\hline 44603 & suture of small intestine (enterorrhaphy) for perforated ulcer & $\mathrm{x}$ & \\
\hline 44605 & suture of large intestine (colorrhaphy) for perforated ulcer & $\mathrm{x}$ & \\
\hline 74240 & Radiologic examination, GI tract, upper; with or without delayed film, without KUB & $\mathrm{x}$ & \\
\hline 74241 & Radiologic examination, GI tract, upper; with or without delayed films, with KUB & $\mathrm{x}$ & \\
\hline 74245 & Radiologic examination, GI tract, upper; with small bowel, includes multiple serial films & $\mathrm{x}$ & \\
\hline 74246 & $\begin{array}{l}\text { Radiologic examination, GI tract, upper, air contrast, with specific high density barium, effervescent agent, with } \\
\text { or without glycagon; with or without delayed films, with KUB }\end{array}$ & $\mathrm{x}$ & \\
\hline 74247 & $\begin{array}{l}\text { Radiologic examination, GI tract, upper, air contrast, with specific high density barium, effervescent agent, with } \\
\text { or without glycagon; with or without delayed films, without KUB }\end{array}$ & $\mathrm{x}$ & \\
\hline 74249 & $\begin{array}{l}\text { Radiologic examination, GI tract, upper, air contrast, with specific high density barium, effervescent agent, with } \\
\text { or without glycagon; with small bowel follow-through }\end{array}$ & $\mathrm{x}$ & \\
\hline
\end{tabular}

a Patients with any GI event in the 12-month pretreatment period were excluded.

${ }^{b}$ Patients with an upper GI event during the first 4 months posttreatment are cases.

$C P T=$ Current Procedural Terminology; GI = gastrointestinal; ICD-9-CM=International Classification of Diseases, Ninth Revision, Clinical Modification; NEC=not elsewhere classifiable; NOS = not otherwise specified. 